\title{
COMPARATIVE ANALYSIS OF BLEVE MECHANICAL ENERGY AND OVERPRESSURE MODELLING
}

\author{
Behrouz Hemmatian, Eulàlia Planas, Joaquim Casal* \\ Centre for Technological Risk Studies (CERTEC), Universitat Politècnica de Catalunya- \\ BarcelonaTech, Diagonal 647, 08028 Barcelona, Catalonia, Spain
}

\begin{abstract}
A mechanical effects of a BLEVE are overpressure and ejection of fragments. Although fragments reach much longer distances, peak overpressure can be very strong over a certain area. Diverse authors have proposed methodologies for the estimation of the explosion energy and peak overpressure from these type of explosions, based on different thermodynamic and physical assumptions. Here these methodologies are commented and compared. Their predictions, which show an important scattering, are checked by comparison with two sets of experimental data taken from the literature. The results obtained indicate that none of the models take into account Reid's theory. The models based on ideal gas behaviour and constant volume energy addition, isentropic expansion and isothermal expansion give quite conservative (i.e., high) values of both energy released and overpressure, while those assuming real gas behaviour and adiabatic irreversible expansion give lower values, much closer to the real/experimental ones. The diverse uncertainty factors affecting the prediction of peak overpressure are also commented.
\end{abstract}

Keywords: vessel explosion, explosion energy, blast overpressure, pressure wave.

* Corresponding author. Tel.: +34934016 704.

E-mail address: joaquim.casal@upc.edu (J. Casal). 


\section{Introduction}

A boiling liquid expanding vapour explosion (BLEVE) is one of the severe major accidents that can happen in the process industry or during the transport of hazardous substances. This type of explosion occurs when a vessel containing a superheated liquid fails. At that moment, the vapour inside the vessel will expand and the superheated liquid will experience a flash vaporization. The expansion of vapour (or gas; in this paper the word "vapour" will be used) will cause a sudden volume increase that will create an overpressure wave. In such explosions, the energy stored in the liquid and vapour phases is devoted essentially to break the vessel, to give kinetic energy to the ejected fragments and to generate a pressure wave. A BLEVE should not be confused with a fireball, a completely different phenomenon which often follows these explosions (Hemmatian et al, 2016).

The common method to predict the most important effect produced by a BLEVE, i.e. the peak overpressure, consists in determining the total mechanical energy released by the explosion. Then, assuming that a certain percentage of this energy is converted into a pressure wave, the peak overpressure can be estimated by the method of the TNT equivalent mass, Sachs scaled distance curve or other similar characteristic curves (Casal, 2008; Crowl, 2010).

There is not a unique way to calculate the mechanical energy released in a BLEVE, and several models can be found in the literature. The differences among them rely, basically, on the thermodynamic assumptions on which they are based (Planas and Casal, 2015). Few attempts have been made to compare the results given by the diverse models with the rather scarce experimental data available and, mostly, the comparison has been made in terms of the peak overpressure generated (Crowl, 2002; Abbasi et al., 2007; Bubbico and Marchini, 2008; Ogle et al., 2012; Laboureur et al., 2014).

In this paper the models presented in the literature to estimate the BLEVE mechanical energy and overpressure effects are reviewed. Their predictions concerning the mechanical energy released are compared and, after compiling some experimental data on BLEVEs, a comparison is also performed in terms of overpressure estimation. The effect of the fraction of the energy released that is invested in creating 
overpressure, and of considering only the vapour phase contribution or both the vapour and liquid flash contributions on the results obtained are also evaluated.

\section{BLEVE mechanical energy and overpressure modelling}

During the failure of a vessel containing a superheated liquid, the expansion of the vapour phase present before the burst plus the partial flashing of the liquid and subsequent expansion of the formed vapour, generate the mechanical energy. The way in which this mechanical energy is computed depends mainly on the thermodynamic assumptions that are made. These assumptions can be summarized as follows:

- Constant volume energy addition (CV)

- Isothermal expansion (IE)

- Thermodynamic availability (TA)

- Ideal gas behaviour and isentropic expansion (IISE)

- Real gas behaviour and isentropic expansion (RISE)

- Real gas behaviour and adiabatic irreversible expansion (RAIE).

The first four assumptions consider ideal gas behaviour, while the last two consider real gas. To take into account the energy associated to the flashing fraction $(f)$ of the superheated liquid, the mass of liquid that will be converted into vapour when reducing the pressure has to be estimated. Its volume at the pressure just before the explosion $\left(V_{f}\right)$ has to be added to the one of the previously existing vapour phase $(V)$ to obtain the total volume of vapour contributing to the expansion energy $\left(V^{*}\right)$ (Casal, 2008):

$$
\begin{gathered}
f=1-\exp \left[-2.63 \cdot \frac{c_{p_{L, T b}}}{\Delta h_{v, T b}} \cdot\left(T_{c}-T_{b}\right) \cdot\left(1-\left(\frac{T_{c}-T}{T_{c}-T_{b}}\right)^{0.38}\right)\right] \\
V_{f}=L \cdot f \cdot\left(\frac{\rho_{L}}{\rho_{V}}\right) \\
V^{*}=V+V_{f}
\end{gathered}
$$

The equations required to calculate the mechanical energy associated to the vapour phase $(E)$ or to the sum of vapour and flashing liquid contributions $\left(E^{*}\right)$ for each of the thermodynamic assumptions listed before have been summarized in the Appendix. 
The method based on constant volume energy addition (CV), proposed by Brode (1959), is the simplest one and provides the energy that can potentially be released in the explosion as the amount of energy needed to pressurize the vapour from ambient pressure to the pressure just before the explosion, considering a constant volume process. The isothermal expansion (IE) assumption (Smith and Van Ness, 1996) considers that, during the explosion, the expansion of the gas is so fast that there cannot be any changes in the temperature. This is the approach which provides usually the largest values for the explosion energy. Crowl $(1991,1992)$ proposed the thermodynamic availability (TA) method to provide the maximum mechanical energy that could be obtained from a fixed mass of material (ideal gas) as it reversibly changed from burst to ambient conditions. Prugh (1991) proposed to calculate the explosion energy considering that the vapour behaves as an ideal gas and its expansion is adiabatic and reversible (i.e. isentropic) (IISE assumption). Other authors, such as Roberts (2000) or the CCPS (2010), consider the isentropic expansion of the vapour but take the real properties of the material (RISE). Finally, Planas et al. (2004) and Casal and Salla (2006) considered that the assumption of an adiabatic and irreversible expansion process with the real properties of the substance (RAIE assumption) would be the most realistic approach, taking into account the obvious non-reversible and non-isentropic nature of the explosion phenomenon.

All these methods provide an estimation of the total energy released in the BLEVE explosion. Nevertheless, this energy is not fully converted into pressure wave as it is also used to, among others, break the vessel, to deform the fragments generated, to provide kinetic energy to the ejected projectiles and to heat the environment (although this part is negligible), etc. The energy distribution among all these factors depends on the particular conditions of each explosion; the percentage devoted to the generation of the pressure wave (usually expressed as parts per unit, from now on $\beta$ ) can range from $80 \%$ in the case of fragile fracture of the vessel (quite rare) to $40 \%$ in case of a ductile fracture, when large fragments of the vessel are ejected, which is the most common case. Taking into account that the goal is to compare the effect of the thermodynamic assumptions on the results given by the diverse models considered, a uniform value $\beta=0.4$ was considered (i.e., it is assumed that $40 \%$ of the mechanical energy released is devoted to create the overpressure wave); this value seems to be adequate, taking into account the relatively good agreement obtained with the 
experimental results (see Section 5). Therefore, the energy released which is converted into pressure wave is:

$$
E_{w}=\beta \cdot E^{*}=0.4 \cdot E^{*}
$$

To convert this energy into overpressure two methods are commonly used, the TNT equivalent mass method and the Sachs scaled distance method. In both cases, a scaled distance needs to be calculated and then, from the corresponding graph (CCPS, 1994; Laboureur et al., 2014), the peak overpressure can be obtained. The corresponding scaled distances can be obtained from equations (5) and (6) (Casal, 2008):

$$
\bar{R}=\frac{r_{0}}{\left(2.14 \cdot 10^{-7} \cdot E_{w}\right)^{1 / 3}}
$$

(where $\bar{R}$ is the scaled distance, $2.14 \cdot 10^{-7} \mathrm{~kg}_{\mathrm{TNT}} \cdot \mathrm{J}^{-1}$ corresponds to the blast energy of TNT and $r_{o}$ is the distance between the centre of the explosion and the point at which the overpressure has to be estimated, $\mathrm{m}$ )

$$
R_{s}=r_{0} \cdot\left(\frac{P_{0}}{E_{w}}\right)^{1 / 3}
$$

(where $R_{S}$ is the Sachs scaled distance and $P_{o}$ is the atmospheric pressure, $\mathrm{Pa}$ ).

Although these two methods give only approximate values of the peak overpressure, its use is adequate for a comparative analysis.

\section{Previous comparative analyses}

A few authors have performed a comparative analysis of the aforementioned methodologies (Table 1), based on the predicted value of the energy released or $\Delta P$. It should be mentioned that those authors used different values of $\beta$ and scaled distance curves for the various thermodynamic assumptions in order to calculate $\Delta P$ and do their analyses.

Table 1. Thermodynamic assumptions considered in different studies.

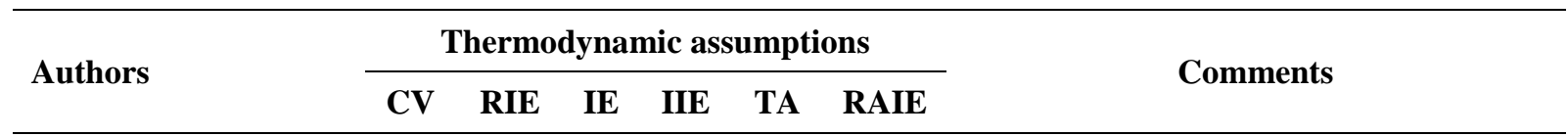




\begin{tabular}{|c|c|c|c|c|c|c|c|}
\hline $\begin{array}{l}\text { Abbasi et al. } \\
(2007)\end{array}$ & & $\checkmark$ & & $\checkmark$ & & $\checkmark$ & $\begin{array}{l}\text { - Comparison of models in terms of } \\
\text { mechanical energy } \\
\text { - Substance used: propane } \\
\text { - } \beta \text { not used }(\beta=1)\end{array}$ \\
\hline $\begin{array}{l}\text { Bubbico and Marchini } \\
\text { (2008) }\end{array}$ & $\checkmark$ & $\checkmark$ & & & $\checkmark$ & $\checkmark$ & $\begin{array}{l}\text { - Comparison of models in terms of } \\
\text { energy and overpressure }(\Delta \mathrm{P}) \\
\text { - Substance used: propane } \\
\text { - } \beta=0.5 \\
\text { - Scaled distance curve used: TNT curve }\end{array}$ \\
\hline $\begin{array}{l}\text { Crowl } \\
(2010)\end{array}$ & $\checkmark$ & & $\checkmark$ & $\checkmark$ & $\checkmark$ & & $\begin{array}{l}\text { - Comparison of models in terms of } \\
\text { mechanical energy } \\
\text { - Substance used: compressed inert gas } \\
\text { - } \beta \text { not used }(\beta=1)\end{array}$ \\
\hline $\begin{array}{l}\text { Ogle et al. } \\
(2012)\end{array}$ & & $\checkmark$ & & $\checkmark$ & $\checkmark$ & $\checkmark$ & $\begin{array}{l}\text { - Comparison of models in terms of } \\
\text { mechanical energy } \\
\text { - Substances used: propane; chlorine; } \\
\text { ammonia; R134a } \\
\text { - } \beta \text { not used }(\beta=1)\end{array}$ \\
\hline $\begin{array}{l}\text { Laboureur et al. } \\
\text { (2014) }\end{array}$ & & $\checkmark$ & & $\checkmark$ & & $\checkmark$ & $\begin{array}{l}\text { - Comparison of models in terms of } \\
\text { overpressure }(\Delta P) \\
\text { - Substances used: propane and butane } \\
\text { - } \beta=0.07,0.4,0.5 \\
\text { - Scaled distance used: TNT and Sachs } \\
\text { curves }\end{array}$ \\
\hline
\end{tabular}

Abbasi et al. (2007) performed a review of several of these methodologies. According to their results, if the burst energy of a vessel filled with propane was equal to $1 \mathrm{~kJ}$ as per the method based on ideal gas and isentropic expansion assumption (e.g. Prugh, 1991), then it would be about $1.1 \mathrm{~kJ}$ as per the method based on real gas behaviour and isentropic expansion (e.g. CCPS, 2010) and $0.4 \mathrm{~kJ}$ as per the method based on real gas behaviour and adiabatic irreversible expansion (Planas Cuchi et al., 2004). Their comparative study shows that this last method is less conservative than the other ones, giving lower values probably much closer to the real value.

Bubbico and Marchini (2008) studied an accident involving the explosion of a vessel filled with propane. They applied different methods to calculate the explosion energy and compared the corresponding calculated overpressures with the value obtained from the analysis of the real case at two different distances. Comparing the estimated results with the real case, they observed that the methodologies based on real gas behaviour and adiabatic irreversible expansion assumption gave the closest values; they noted that the constant volume energy addition or isentropic expansion 
assumptions, even if far from the real phenomenon, might be convenient to estimate the maximum overpressure that could be expected.

Crowl (2010) also compared the results obtained using the thermodynamic availability concept with those from three other methods, those based on ideal gas behaviour and isothermal expansion, ideal gas behaviour and isentropic expansion and constant volume energy addition assumptions. According to this analysis, the isothermal method predicts higher overpressure values than the other three methods, and assuming isentropic expansion is the one which predicts the lowest values because it considers the final temperature much lower than the surroundings one. The author obtained the following conclusion for the value of the energy of expansion calculated from the diverse approaches:

Isothermal approach $>$ constant volume energy addition approach $>$ thermodynamic availability approach > isentropic approach.

Ogle et al. (2012) followed the work of Crowl (1992), calculating the maximum energy which could be released by a BLEVE. They applied thermodynamic availability to different fluids and compared the results with those obtained from other methodologies: ideal gas behaviour and isentropic expansion (Prugh, 1991), real gas behaviour and isentropic expansion (CCPS, 2010) and real gas behaviour and adiabatic irreversible expansion (Planas Cuchi et al., 2004). The energy of expansion calculated by the thermodynamic availability method was much larger than that predicted by the other methods, and the real gas behaviour and adiabatic irreversible expansion gave the lowest energy; the other two methods gave similar values, except when approaching the critical temperature. However, the relative magnitude changed for each fluid.

Finally, Laboureur et al. (2014) performed also a comparative study. They classified the experimental data into three different groups in terms of TNT equivalent mass: large scale $\left(\mathrm{m}_{\mathrm{TNT}}>1 \mathrm{~kg}\right)$; mid-scale $\left(\mathrm{m}_{\mathrm{TNT}}=1 \mathrm{~kg}\right)$ and small-scale $\left(\mathrm{m}_{\mathrm{TNT}}<1 \mathrm{~kg}\right)$. The methodologies based on real gas behaviour and adiabatic irreversible expansion assumption (Planas Cuchi et al., 2004; Casal and Salla, 2006) gave the best fit in all cases. However, they also suggested that the methodologies based on ideal gas behaviour and isentropic expansion assumption (e.g. Prugh, 1991) could be used in a 
rather conservative approach, even though what their results give really should be considered in fact the theoretical upper limit of the energy released.

All these studies coincided in that the methods assuming an ideal behaviour give higher values than the few ones assuming a real behaviour. However, a more detailed and systematic analysis, comparing the diverse predictions with experimental data obtained at a middle scale, was still required to establish the limitations, validity and usefulness of the different methodologies.

\section{Mechanical energy according to the diverse models}

To study the effects predicted by the diverse models mentioned above, a scenario was defined for a $45 \mathrm{~m}^{3}$ vessel filled up to a $20 \%, 50 \%$, and $80 \%$ of its total volume with the ten substances most commonly found in BLEVE accidents according to a previous historical survey (Hemmatian et al., 2015): propane, butane, methane, water, vinyl chloride, chlorine, ethylene, ammonia, propylene and ethylene oxide. It was assumed that the vessel was heated up by an external thermal source and that it could break at any temperature up to the critical one; therefore, the released energy was calculated for all these temperatures. NIST Reference Fluid Properties (Version 9.1; Lemmon et al., 2007) was used for the thermodynamic calculations. Fig.1 summarizes the results obtained for the case of $50 \%$ filling degree. The liquid superheating energy (SE) method (Casal and Salla, 2006) was not shown in this set of calculations because this method does not give the overall energy released, but just the energy invested in creating the overpressure wave. However, it is included in this study (see Section 6).

Based on Fig. 1, the results show that the method based on real gas behaviour and adiabatic irreversible expansion gives the lowest values for energy release for all the substances, with a good agreement with the results of some of the previously mentioned studies (Bubbico and Marchini, 2008; Laboureur et al., 2014). As for the method based on constant volume energy addition, it gives the largest values in the cases of propane, butane, vinyl chloride, propylene and ethylene oxide, which have lower values of $\gamma$ (ratio of gas specific heats); when the value of $\gamma$ is higher than 1.2, this method predicts lower values of the energy released than those obtained from the method based on isothermal expansion; thus, this latter method gives the largest amount for the rest of substances (methane, water, chlorine, ethylene and ammonia). 
This is due to the fact that $\gamma$ appears in the denominator of the constant volume energy addition equation (Eqs. (A-1) and (A-2), see Appendix) and does not affect the isothermal model; therefore, for large $\gamma$ values the $\mathrm{CV}$ model tends to provide lower values. The method based on thermodynamic availability gives similar results than the one based on isothermal expansion; however, the former method has lower energy value at the same condition than the latter one. 

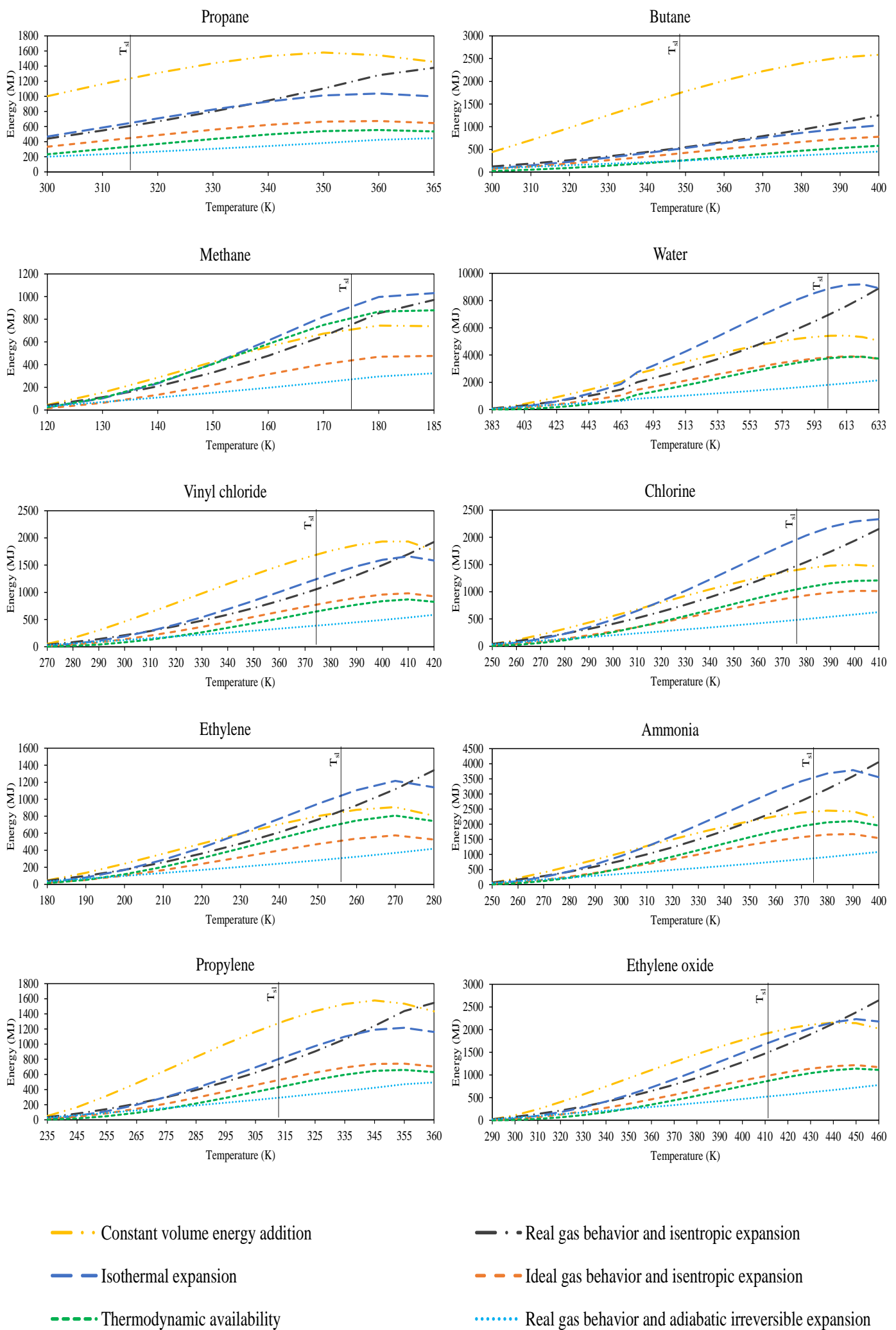

Fig. 1 - Mechanical energy released by the explosion at different temperatures and 50\% initial filling degree (just before the explosion), based on the diverse thermodynamic assumptions for 10 different substances. The vertical line in the graph indicates the corresponding value of the superheat limit temperature (Salla et al., 2006). 
Finally, the method based on real gas behaviour and adiabatic irreversible expansion shows a much smaller change as a function of temperature than the other ones.

All aforementioned methods have the same behaviour as a function of different filling degrees for various substances. During the heating of a vessel, two simultaneous phenomena occur: expansion and evaporation of the contained liquid. If in a vessel there is initially a high level of liquid, this level will increase because of heating and subsequent expansion. In some very specific situations, the vessel could become fully filled with the liquid; in such a case, further heating would imply the failure of the vessel due to the increase of pressure, the liquid being an incompressible fluid, and the model analysis here will not be applicable anymore as the relationship between pressure and temperature will become completely different. This situation, which occurred in Els Alfacs accident (Casal, 2008), could also be found in the case of certain pipelines sections between two blocking valves.

Another feature that can be mentioned is the fact that none of these methods shows any discontinuity when the superheat limit temperature is reached. This does not agree with the theory proposed by Reid (1979). According to it, for the explosion to be a BLEVE this temperature should be reached; then, the explosion mechanism would be different and its effects would be much more severe. This would determine the minimum pressure/temperature at which a BLEVE could occur. However, it seems that this condition should be restricted to laboratory small scale tests.

\section{BLEVE experimental data}

Two sets of BLEVE experiments from literature (Johnson et al., 1990 and Birk et al. 2006, 2007) were used in order to check the performance of the different models previously commented. They were considered to be a good representative of large scale systems in real cases (Birk, 2012).

Birk et al. used $2 \mathrm{~m}^{3}$ vessels which contained liquid propane. The vessels were engulfed by a set of jet-fires and the overpressures at various distances $\left(P_{s}\right)$ were measured, both in the axial and transversal directions (this overpressure was that associated to the first registered peak, corresponding to the expansion of the previous existing vapour); another reported parameter was the vessel failure pressure $\left(P_{\text {rup }}\right)$. A summary of these experimental results are shown in Table 2. 
Table 2. Experiments performed by Birk et al. with propane in a $2 \mathrm{~m}^{3}$ vessel (Birk et al., 2006 and 2007; Laboureur et al., 2014).

\begin{tabular}{cccll}
\hline Test & $\begin{array}{c}\text { Filling } \\
\text { degree } \\
(\boldsymbol{\%})\end{array}$ & $\begin{array}{c}\boldsymbol{P}_{\text {rupture }} \\
(\mathbf{k P a})\end{array}$ & $\begin{array}{l}\boldsymbol{r}_{\boldsymbol{o}} \text { (distance between the } \\
\text { explosion and } \\
\text { measurement point, m) }\end{array}$ & \multicolumn{1}{c}{$\begin{array}{c}\boldsymbol{P}_{\boldsymbol{s}} \text { (overpressure at a } \\
\left.\text { distance } \boldsymbol{r}_{\boldsymbol{o}}, \mathbf{k P a}\right)\end{array}$} \\
\hline B1 & 17 & 1863 & $\begin{array}{l}10 / 20 / 30(\mathrm{E}) / 30(\mathrm{~S}) / 40(\mathrm{E}) / \\
40(\mathrm{~S})\end{array}$ & $6.65 / 3.5 / 3.11 / 4.19 / 2.11 / 2.73$ \\
B2 & 35 & 1846 & $10 / 20 / 30 / 40(\mathrm{E}) / 40(\mathrm{~S})$ & $3.97 / 3.78 / 2.29 / 1.48 / 2.13$ \\
B3 & 13 & 1699 & $10 / 20 / 40(\mathrm{E}) / 40(\mathrm{~S})$ & $5.29 / 2.75 / 1.72 / 1.83$ \\
B4 & 21 & 1894 & $10 / 40$ & $5.02 / 1.675$ \\
B5 & 12 & 1573 & $10 / 20 / 30 / 40$ & $4.13 / 2.58 / 1.58 / 1.31$ \\
B6 & 51 & 1803 & $\begin{array}{l}10 / 20 / 30(\mathrm{E}) / 30(\mathrm{~S}) / 40(\mathrm{E}) / \\
40(\mathrm{~S})\end{array}$ & $13.11 / 8.95 / 6.03 / 2.99 / 3.37 / 4.06$ \\
B7 & 52 & 1563 & $10 / 20 / 30 / 40$ & $4.563 / 3.4 / 1.93 / 1.58$ \\
B8 & 53 & 1813 & $10 / 20 / 30(\mathrm{E}) / 30(\mathrm{~S}) / 40(\mathrm{E}) /$ & $4.15 / 2.99 / 2.99 / 2.29 / 2.6 / 0.64$ \\
B9 & 61 & 1858 & $10 / 20 / 30 / 40$ & $5.44 / 5.05 / 3.59 / 2.7$ \\
\hline
\end{tabular}

S: transversal direction

E: axial direction

Johnson et al. (1990) performed a series of tests with butane and propane (Table 3). They used electric immersion heaters for heating up the vessels; a polymeric heat insulator covered the vessels to reduce heat losses. Detonation of a short length of linear shaped high explosive charge provoked the failure of the tanks. In one of the tests (J6) the experimental fluid was changed from butane to propane, without changing the vessel capacity. These authors also performed one test by increasing the volume of the container $\left(10.8 \mathrm{~m}^{3}\right)$ and keeping the same amount of butane $(2000 \mathrm{~kg})$ such as in another test (J5). In another experiment (J3), they reduced the amount of butane to $1000 \mathrm{~kg}$ in the same vessel volume. In these tests, the overpressures generated by the expansion of the vapour phase present before the burst and by the flash vaporization of the liquid often combined into a single peak.

Table 3. Experiments performed by Johnson et al. with propane in a $2 \mathrm{~m}^{3}$ vessel (Johnson et al., 1990).

\begin{tabular}{lllllccc}
\hline Test & $\begin{array}{l}\text { Filling } \\
\text { degree }\end{array}$ & Fluid & $m(\mathrm{~kg})$ & $V\left(\mathbf{m}^{3}\right)$ & $\begin{array}{c}\boldsymbol{P}_{\text {rupture }} \\
(\mathbf{k P a})\end{array}$ & $\begin{array}{c}\boldsymbol{r}_{o} \text { (distance } \\
\text { between the }\end{array}$ & $\begin{array}{c}\boldsymbol{P}_{s} \\
\text { (overpressure }\end{array}$ \\
\hline
\end{tabular}




\begin{tabular}{|c|c|c|c|c|c|c|c|}
\hline & $(\%)$ & & & & & $\begin{array}{c}\text { explosion and } \\
\text { measurement } \\
\text { point, m) }\end{array}$ & $\begin{array}{c}\text { at a distance } r_{o}, \\
\mathbf{k P a})\end{array}$ \\
\hline $\mathrm{J} 1$ & 75 & Butane & 2000 & 5.659 & 1460 & $25 / 100 / 150$ & $6.2 / 1.3 / 1.1$ \\
\hline $\mathrm{J} 2$ & 76 & Butane & 2000 & 5.659 & 1510 & $25 / 50 / 100 / 150$ & 6.3/3.9/0.9/0.6 \\
\hline $\mathrm{J} 3$ & 38 & Butane & 1000 & 5.659 & 1520 & $25 / 50 / 100 / 150$ & $5 / 2.8 / 1.2 / 0.8$ \\
\hline $\mathrm{J} 4$ & 68 & Butane & 2000 & 5.659 & 770 & $25 / 50 / 100 / 150$ & 1/0.5/0.17/0.15 \\
\hline J5 & 40 & Butane & 2000 & 10.796 & 1510 & $25 / 50 / 100 / 150$ & $8.2 / 3.4 / 1.4 / 0.7$ \\
\hline J6 & 77 & Propane & 2000 & 5.659 & 1520 & $25 / 50 / 100 / 150$ & 2.3/1.2/0.3/0.3 \\
\hline $\mathrm{J} 7$ & 76 & Butane & 2000 & 5.659 & 1520 & $25 / 50 / 100$ & $7 / 3.4 / 1.3$ \\
\hline
\end{tabular}

\section{Comparative analysis}

Here a constant $\beta$ factor -fraction of the energy released converted into a pressure wave- is considered and set equal to $40 \%$ ( $\beta=0.4$ ) (Planas-Cuchi et al. 2004), even if different values had been proposed in the diverse methods (in fact, most authors have considered $100 \%(\beta=1)$ in a quite conservative and hence non-realistic approach)This constant value was used to obtain a better comparison of the various thermodynamic assumptions corresponding to the diverse methods. The two scaled distance curves (the TNT equivalent mass and Sachs scaled distance methods) were used to estimate the overpressure at the different distances. Fig. 2 depicts the procedure.

\begin{tabular}{|c|c|c|}
\hline $\begin{array}{c}\text { Method used for } \\
\text { mechanical energy of } \\
\text { BLEVE }\end{array}$ & $\begin{array}{c}\beta=0.4 \text { as fraction of } \\
\text { energy released } \\
\text { converted into } \\
\text { pressure wave }\end{array}$ & $\begin{array}{c}\Delta P \text { (TNT equivalent } \\
\text { mass curve and Sachs } \\
\text { overpressure distance } \\
\text { curve) }\end{array}$ \\
\hline
\end{tabular}

Fig. 2 - Scheme of the methodology used to calculate the overpressure peak at a certain distance, from the total mechanical energy.

The predicted values of the released mechanical energy of the explosion corresponding to the tests performed by Johnson et al. and Birk et al. are summarized in Fig. 3 and Fig. 4. As it can be observed, the extreme values are obtained from the method based on real gas behaviour and adiabatic irreversible expansion (Planas et al, 2004) (the lowest mechanical energy) and by the method based on constant volume 
energy addition (Brode, 1959) (the largest mechanical energy) as already observed in section 4.

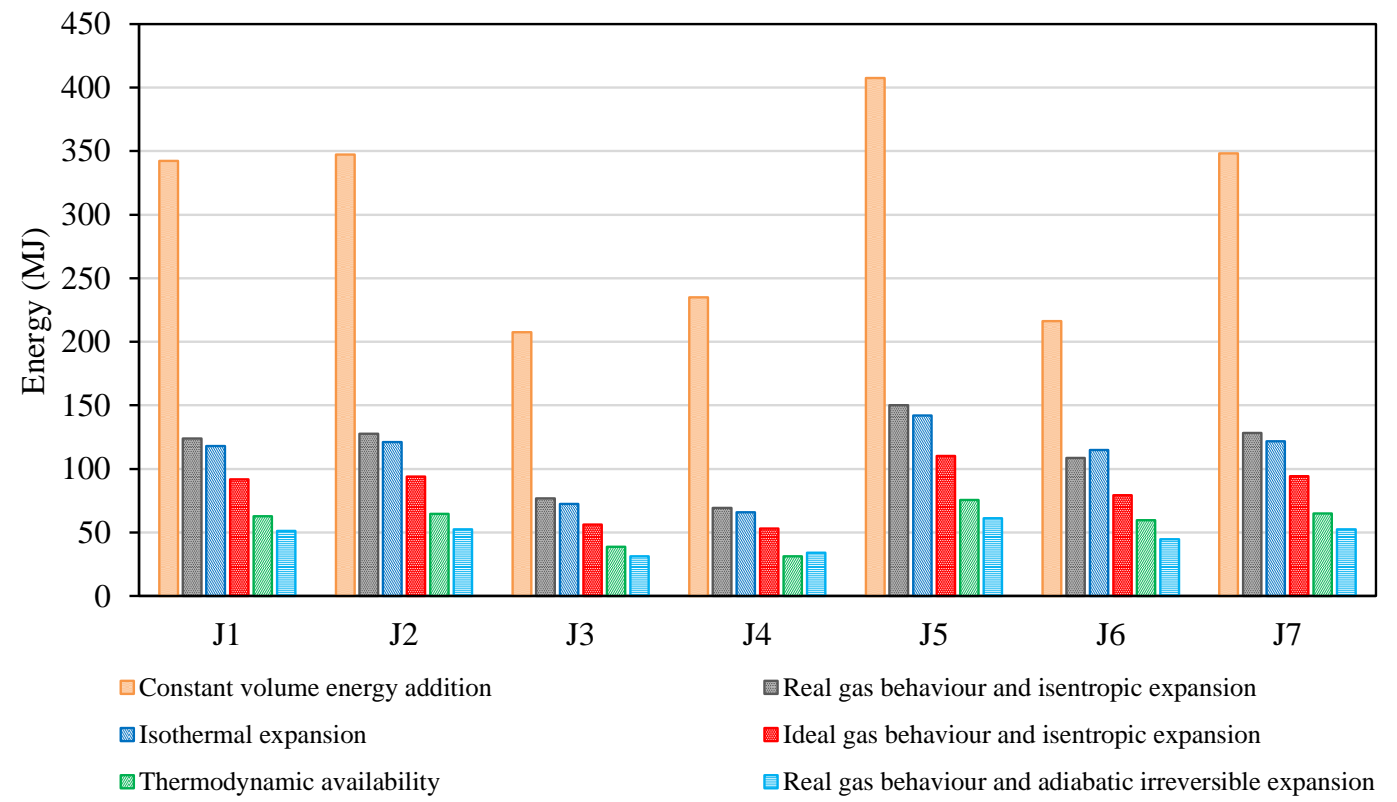

Fig. 3 - Calculated mechanical energy according to the different models for the experiments of Johnson et al. (1990).

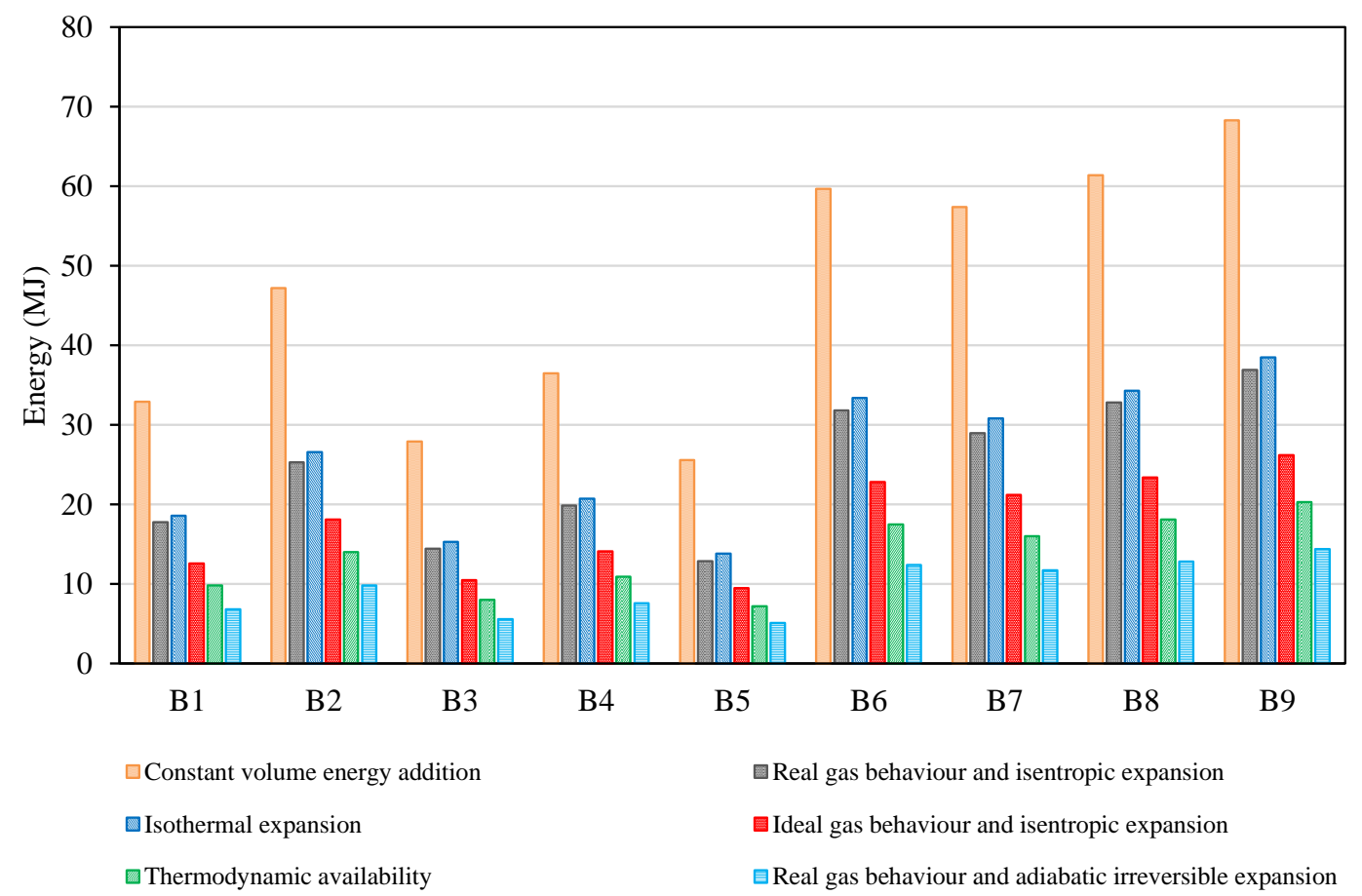

Fig. 4 - Calculated mechanical energy according to the different models for the experiments of Birk et al. $(2006,2007)$. 
The diverse predictions for the overpressure peak are depicted in Fig. 5 and Fig. 6, together with the experimental results of Johnson (1990) and Birk (2006, 2007) respectively . Here, the superheating energy (SE) model is also considered, which is based on the real gas behaviour and adiabatic irreversible expansion assumption. In most of the tests, the experimental results are closer to the predictions from the methods proposed by Casal and Salla (2006), Planas-Cuchi et al. (2004) and Crowl (1992), which give relatively similar values, and far from the values predicted by the other four methods.

An atypical result is observed in the case of experiments number $\mathrm{J} 4$ and $\mathrm{J} 6$, which clearly gave a value much lower than those predicted by all methods. Laboureur et al. (2014) found similar large deviations in their calculations. This seems to indicate that something strange could have occurred with these two tests, perhaps a partial loss of containment through a crack just before the final explosion. With experiment B6, the overpressure was exceptionally high as compared to the other tests. It was reported by the authors that it was a two-step BLEVE, and in this case the explosion is more severe. In a two-step BLEVE, the initial crack is trapped in a stronger part of the vessel wall or stopped because of the decreased pressure in the vessel. Then, the liquid inside the vessel can reach the superheat condition due to the rapid pressure drop inside the vessel. The superheat liquid flashes and causes pressure recovery inside the vessel; this phenomenon can produce enough energy and loading on the wall and the crack again starts to grow causing finally the loss of containment and the BLEVE (Abbasi and Abbasi, 2007). In this situation, the vessel might be already weakened by the crack and heating and a larger part of the available energy may be converted to overpressure (higher value of $\beta$ ).

By using the Sachs scaled distance curve, the trend of the calculated overpressure is logically similar to the results obtained by the TNT equivalent mass curve. However, due to the shape and position of the curve, the value for overpressure obtained by the Sachs scaled distance method is about $50 \%$ lower than the one obtained by using the TNT equivalent mass method. 


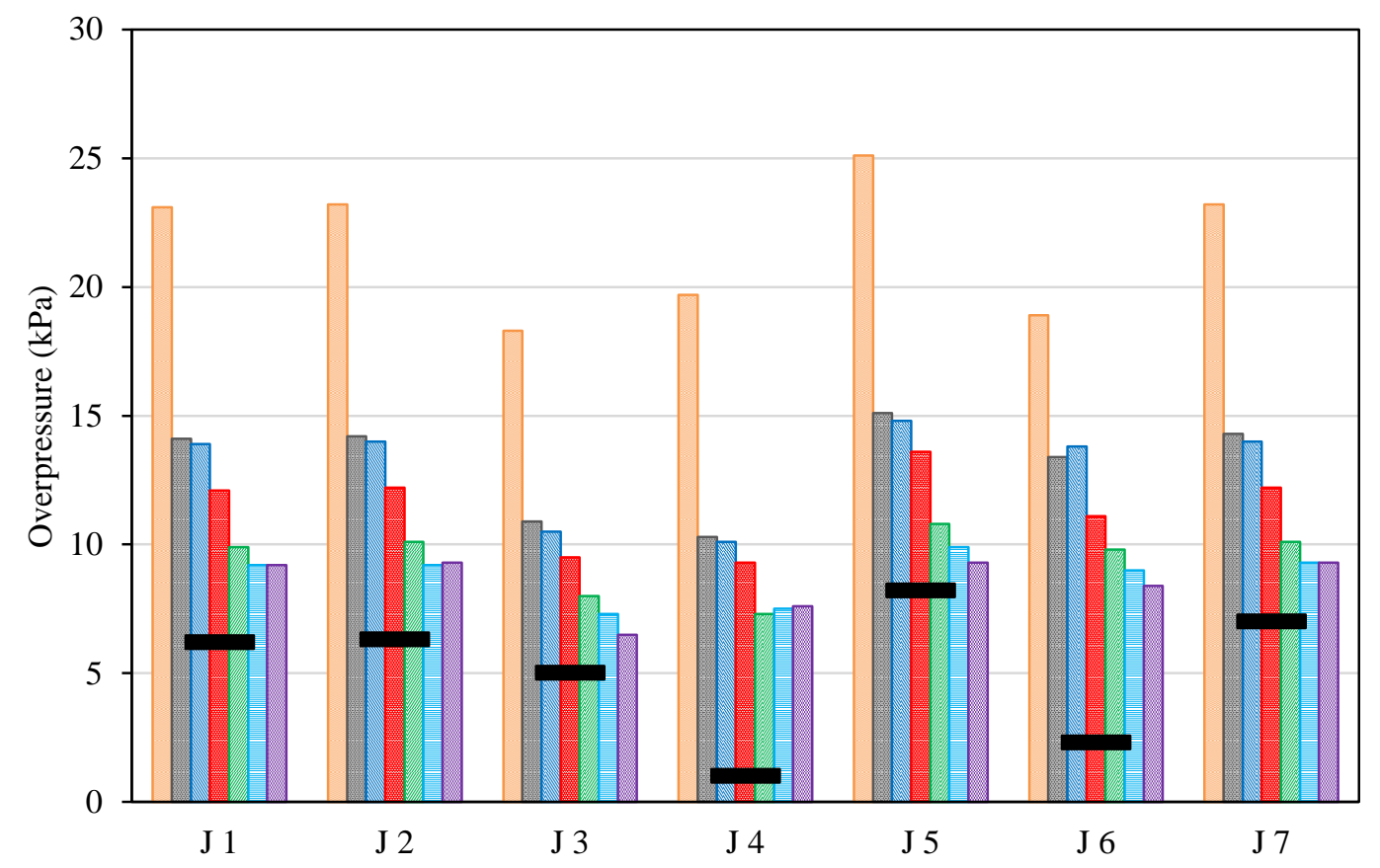

b)

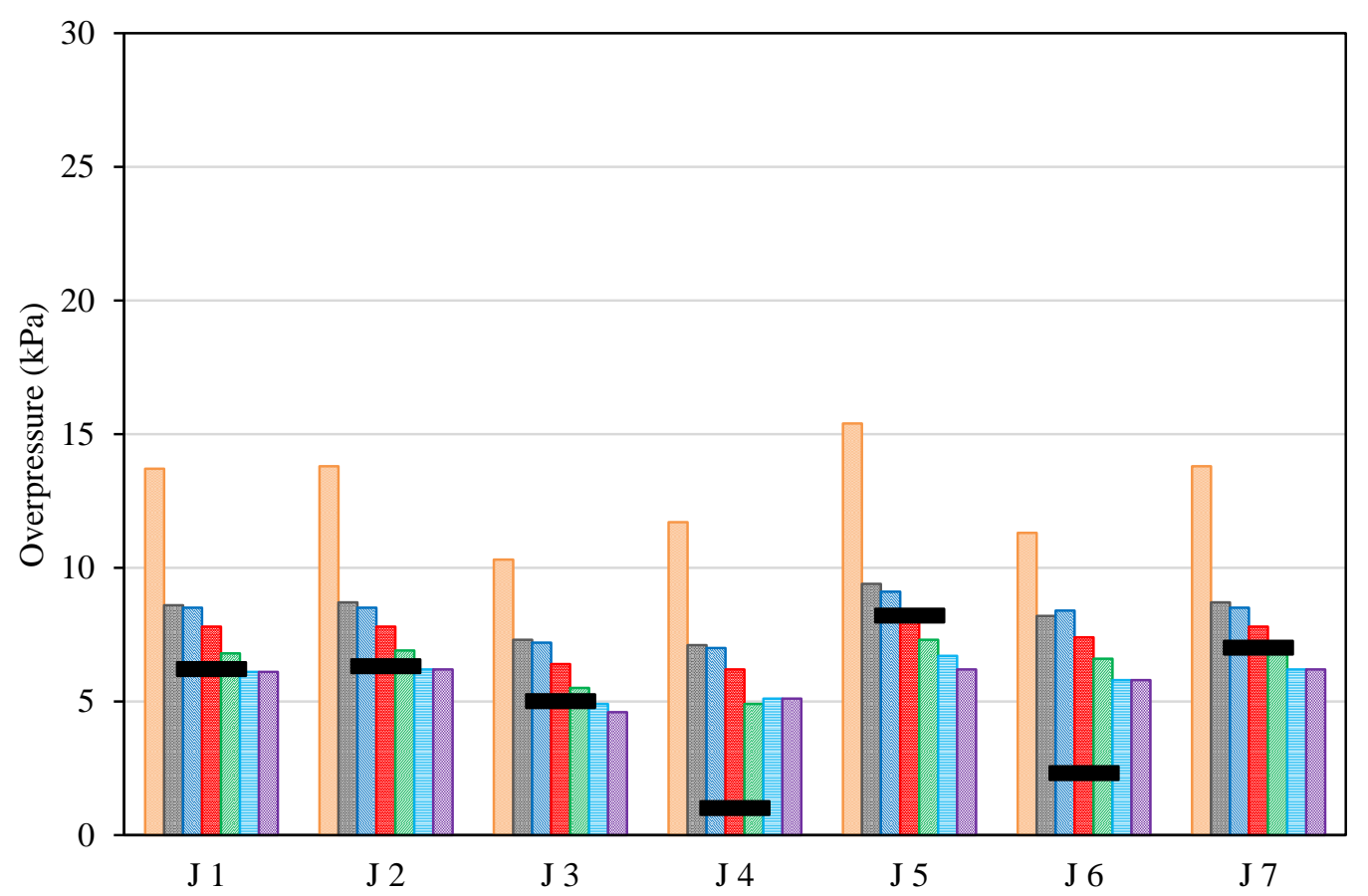

$\square$ Constant volume energy addition

$\square$ Isothermal expansion

$\square$ Thermodynamic availability

$\square$ Liquid superheating energy
Q Real gas behavior and isentropic expansion 目Ideal gas behavior and isentropic expansion 目Real gas behavior and adiabatic irreversible expansion -Experimental measurement

Fig. 5 - Calculated overpressure at a distance of $25 \mathrm{~m}$ simulating the experimental results reported by Johnson et al. (1990), according to a) TNT equivalent mass method; b) Sachs method. 
a)

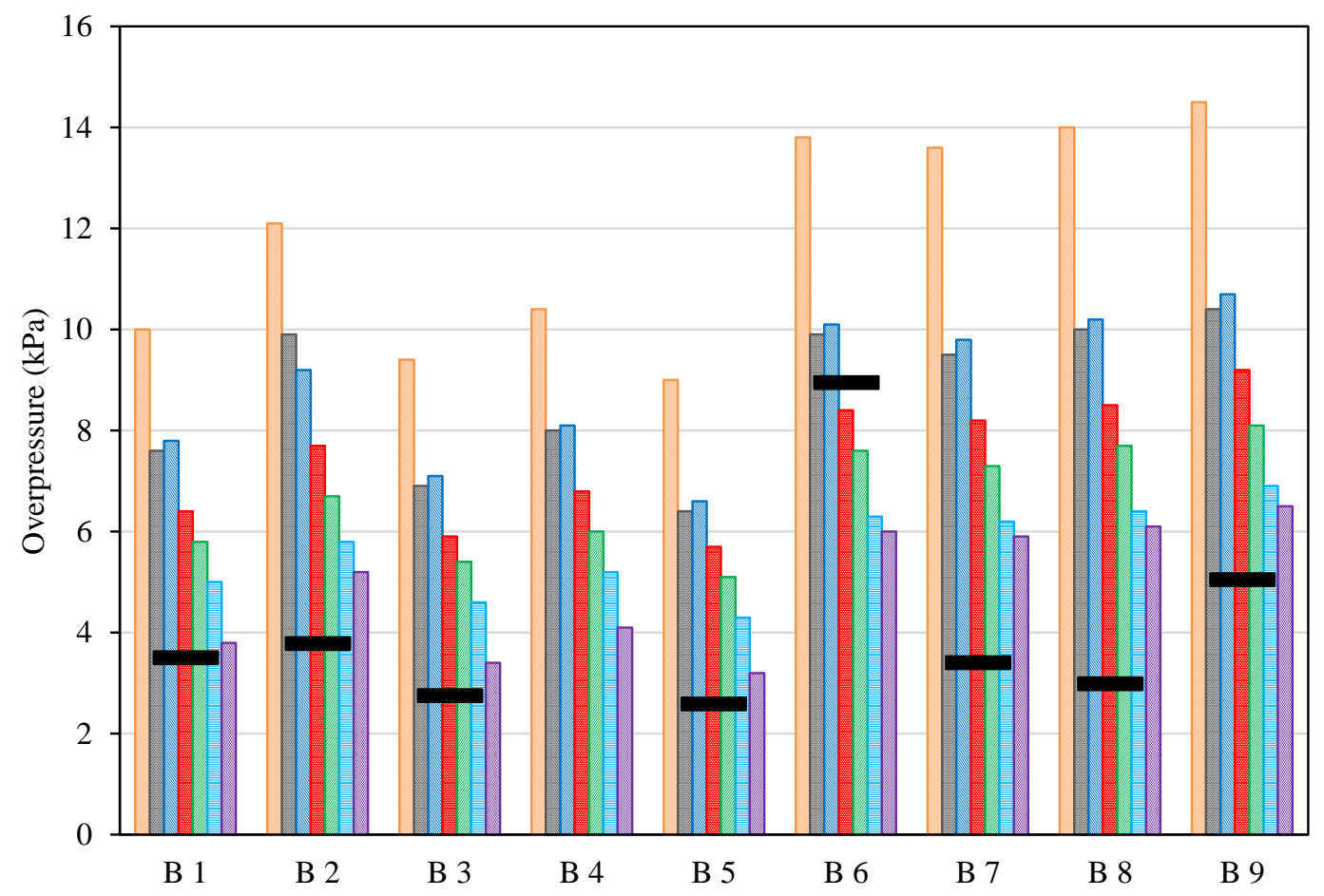

b)

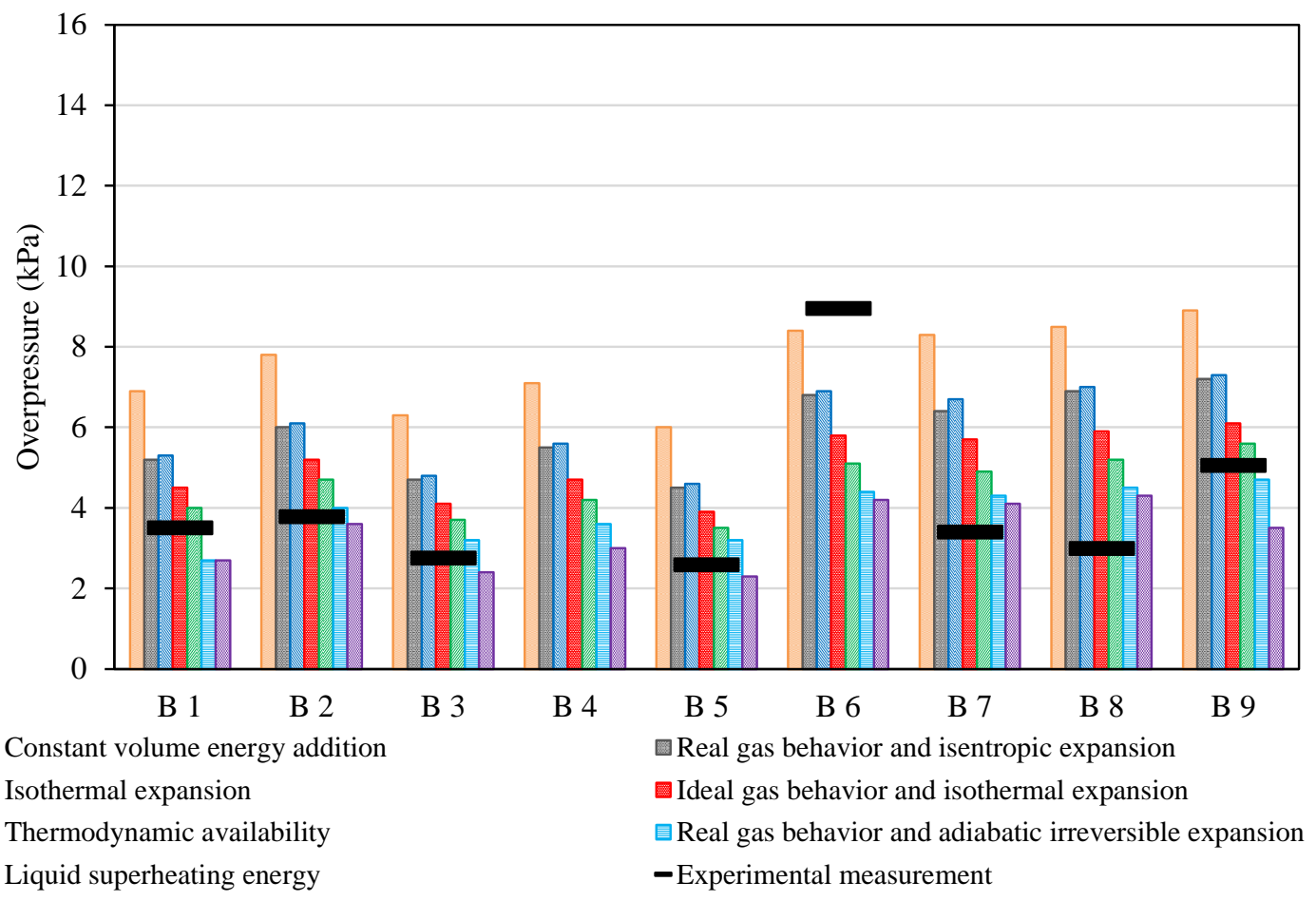

Fig. 6 - Calculated overpressure at a distance of $20 \mathrm{~m}$ simulating the experimental results reported by Birk et al. (2006, 2007), according to: a) TNT equivalent mass method; b) Sachs method. 
Applying all the methods to all experimental tests and measurement distances, the models' performance was analysed by applying the Root Mean Square Deviation (RMSD) (Piñeiro et al., 2008) which represents the mean deviation of predicted values with respect to the observed ones, in the same units as the model variable under evaluation. The RMSD was calculated with respect to all the aforementioned experimental results (Table 4). The results confirm the values obtained in the previous paragraphs. The methods based on real gas behaviour and adiabatic irreversible expansion (Casal and Salla, 2006; Planas Cuchi et al., 2004) still have the lowest RMSD, together with that using thermodynamic availability (Crowl, 1992), this showing a better agreement with experimental data.

Table 4. Overall RMSD considering all thermodynamic assumptions.

\section{Thermodynamic assumption}

\begin{tabular}{lccccccc}
\hline RMSD & CV & RIE & IE & IIE & TA & RAIE & SE \\
\hline $\begin{array}{l}\text { Johnson, TNT curve } \\
\text { Johnson, Sachs }\end{array}$ & 9.2 & 4.6 & 4.5 & 3.6 & 2.7 & 2.3 & 2.2 \\
$\begin{array}{l}\text { curve } \\
\text { Birk, TNT curve }\end{array}$ & 4.5 & 2.1 & 2.1 & 1.7 & 1.3 & 1.3 & 1.3 \\
& 14.3 & 8.7 & 9.6 & 7.4 & 6.3 & 4.9 & 4.1 \\
Birk, Sachs curve & 8.0 & 4.7 & 4.9 & 3.6 & 3.0 & 2.4 & 2.2 \\
\hline
\end{tabular}

Even if the RAIE and SE methods are both based on real gas behaviour and adiabatic irreversible expansion assumption, their RMSD values show some deviations. This can be explained by the fact that the SE method considers only the contribution of liquid flash for calculating the overpressure and as such it will be affected by the initial liquid level in the vessel (also called filling degree). Fig. 7 shows the comparison for the experiments with different filling degrees. 


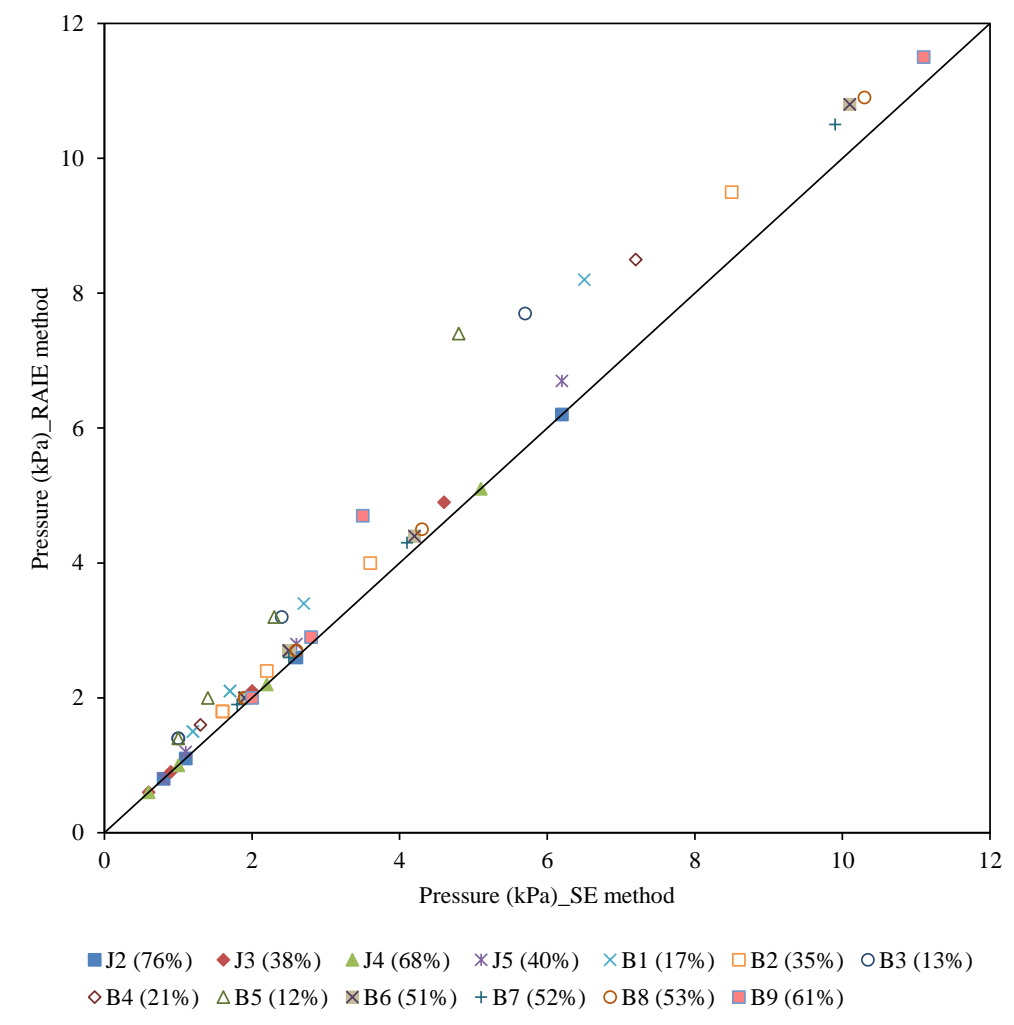

Fig. 7 - Comparison of the SE and RAIE methods at different filling degrees, using the Sachs curve, simulating the experimental results of Johnson et al. (1990) and Birk et al. (2006, 2007).

According to Fig. 7, the experiments with lower filling degrees (i.e., experiments B1, $\mathrm{B} 2, \mathrm{~B} 3, \mathrm{~B} 4$, and B5) gave larger $\Delta \mathrm{P}$ values by using RAIE method, due to the higher quantity of vapour present just before bursting. Therefore, those experiments were studied in detail by comparing them with the corresponding experimental values (Fig. $8)$. The predicted values for the shorter distance $(10 \mathrm{~m})$ had a larger deviation (overprediction) using the RAIE method, compared to the SE method. However, it should be mentioned here that both the TNT and Sachs scaled distance methods introduce a higher error at such a near-field distance. Two contrary issues, underprediction of the SE method due to only considering liquid mass and overprediction by the Sachs curve at close distances, affect the predicted results by the SE method and cause a smaller deviation at any given distance when compared with the results obtained by the RAIE methods at the same distance. 

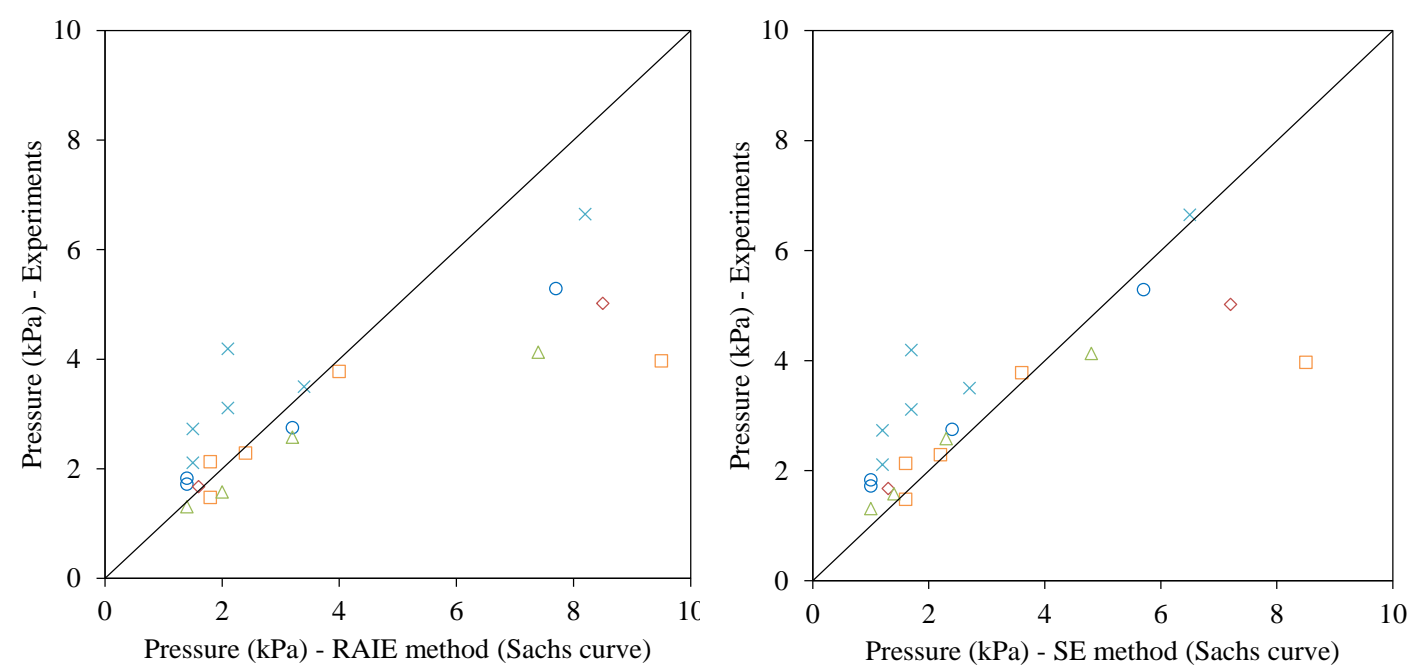

$\times \mathrm{B} 1(17 \%) \square \mathrm{B} 2(35 \%) \circ \mathrm{B} 3(13 \%) \diamond \mathrm{B} 4(21 \%) \triangleleft \mathrm{B} 5(12 \%)$

Fig. 8 - Comparison of the calculated values with the experimental ones for the experiments conducted by Birk et al. $(2006,2007)$ at lower filling degrees.

The convenience of considering the vapour and liquid flash contributions (Fig. 5 and Fig. 6) or only the vapour phase contribution (Fig. 9) was also explored, as there is some uncertainty in the role of the vapour and liquid phases in the resulting blast. It should be noticed that the methods based on real gas behaviour and adiabatic irreversible expansion and on the liquid superheating energy are not considered in this part of analysis due to the fact that they are based always on the contribution of both liquid and vapour phases (even if the SE method finally considers only the contribution of liquid flash). The results do not show a clear trend, although in the case of Birk et al. $(2006,2007)$ tests, Fig. 9 seems to show a better agreement with the theoretical prediction.

With the experiments of Johnson et al (1990), even using the TNT equivalent mass curve (which gives higher overpressure values than the Sachs one), the values obtained considering only the vapour phase contribution clearly underestimate overpressure. In the case of the experiments of Birk et al. $(2006,2007)$, results show a better agreement due to the fact that the filling degrees in the experiments are low.

Another point in which there is some uncertainty is in the directional effect of overpressure. This has been mentioned by both Birk et al. (2007) and Johnson et al. (1990), who, in the near field, registered higher overpressures from the side of the cylindrical vessel which could be up to twice those measured along the longitudinal 
axis; in the far field, the blast was less directional. However, there is not yet enough information on this aspect to quantify it.

a)

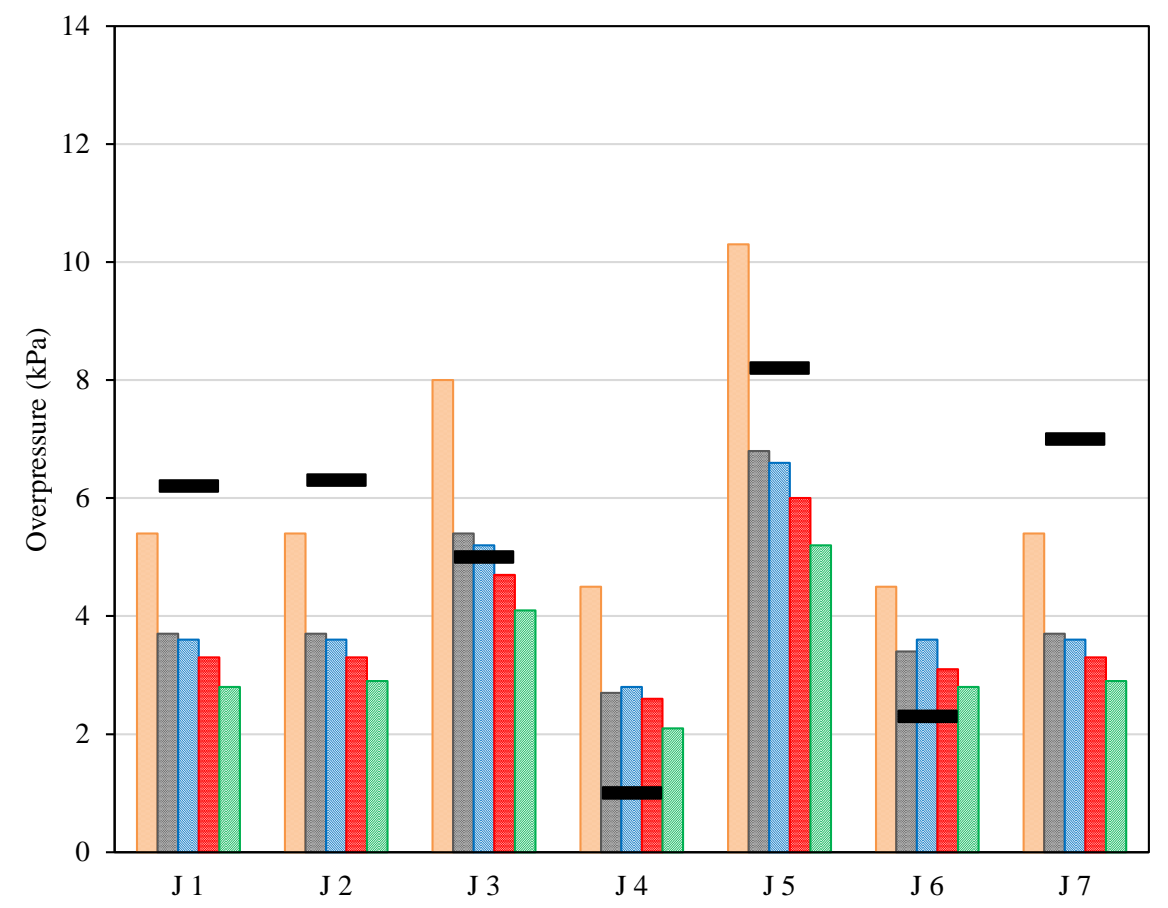

b)

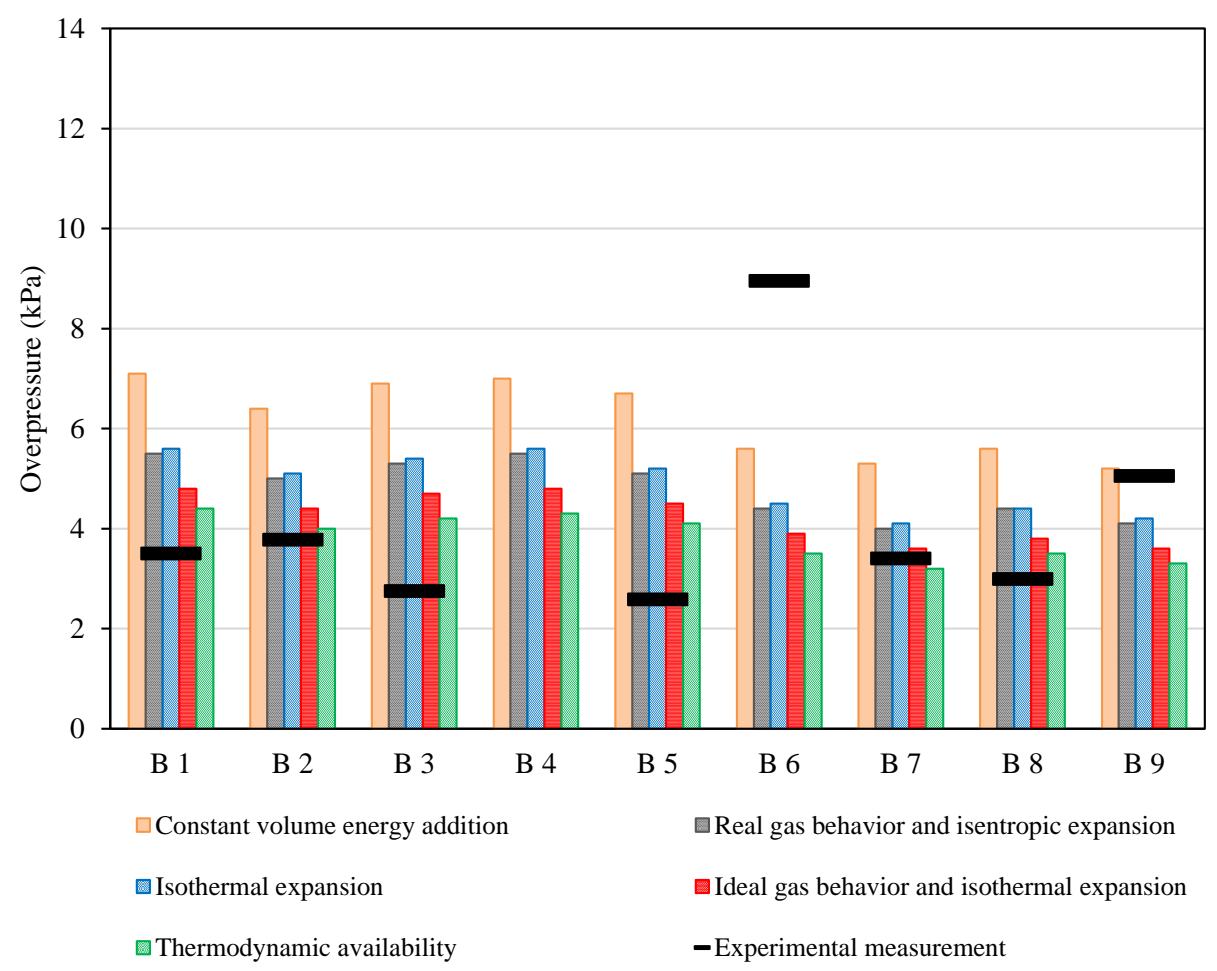


Fig. 9 - Calculated overpressures (TNT equivalent mass curve) based on considering only the vapour phase existing just before the explosion, compared with the experimental values from a) Johnson et al. (1990) and b) Birk et al. (2006, 2007).

\section{Discussion}

The estimation of the blast generated by BLEVEs is subjected to diverse uncertainties, some of which are inevitable. For example, an aspect which can be important is the fraction of the overall energy released in the explosion that is invested in creating the overpressure; it should be taken into account that some of this energy is devoted to breaking the vessel and ejecting the fragments to a certain distance. The value of this fraction will depend on diverse circumstances, such as the conditions of the vessel (corrosion), the way in which it is heated by a fire, the existence of a welding joint, and so on. Thus, some authors assume that it is $40 \%$, some others $50 \%$ and, finally, those more conservative assume $100 \%$. In this paper a fraction of $40 \%$ ( $\beta=0.4$ ) has been assumed, which shouldn't be far from the real value taking into account the results obtained.

Another uncertainty is the heterogeneity of the blast wave, i.e. its directionality (Birk et al., 2007). For cylindrical tanks, the value of overpressure is not the same in the direction of the tank main axis than in the direction perpendicular to it, especially at short distances. This directionality can be related with the pressure in the vessel just before the explosion through the distance reached by a fragment of a given weight; however, this distance can be strongly affected by the fragment shape. However, nowdays this aspect is not sufficiently studied and it cannot be included in any estimation of overpressure.

Furthermore, there is currently some discussion about the respective contributions of the vapour present just before the explosion and that of the vapour generated in the liquid flash (Birk et al., 2007; Laboureur et al., 2015). All the models considered here except the one based on the superheating energy were applied using both contributions. Based on the analysis performed, the following simplifying criterion could be proposed. The contribution of the liquid phase is really significant when the filling degree is larger than 50\%, while at lower filling degrees, the role of the vapour phase present before the burst in the resulting mechanical energy increases. The probability of underestimation is higher if the curves based on the Sachs distance are applied instead of the classical TNT equivalent mass one. 
Additionally, another factor which will add incertitude in any analysis is the amount of material involved in the explosion. Will the tank be filled in an $80 \%$ ? Or, even if it was filled at the beginning of the emergency -for example, a fire heating it-, at the moment of the explosion the degree of filling will have decreased significantly, for example to $40 \%$, due to the release through a safety valve?

Therefore, it should be realized that only approximate estimations of the overpressure wave can really be performed in most cases. However, even if this must be accepted, it is also true that some of the methods proposed in the literature give better predictions than others.

\section{Conclusions}

From the comparative study performed, the following conclusions can be drawn:

1. The results obtained from the diverse models have not shown any discontinuity or significant increase of overpressure when the superheat limit temperature is reached. Thus, none of the methods analysed takes into account a "superheat limit temperature" as a condition to be fulfilled for the explosion to be a BLEVE.

2. The comparative study here developed of the diverse methods proposed by different authors based on different thermodynamic assumptions has shown that, as could be expected, there is an important scattering in the values obtained from them. Looking at these results, a rough classification in two categories is made: a) methods giving a quite conservative (high) value, which in some cases is clearly the upper theoretical value thermodynamically possible, and b) methods giving a lower value, much closer to the real/experimental one.

3. The methods based on constant volume energy addition, isentropic expansion and isothermal expansion are in the first category. These methods should be applied to estimate the maximum overpressure from the explosion. Those assuming real gas behaviour and adiabatic irreversible expansion are in the second one. These latter methods are much closer to real values, as certain analyses of medium and full scale BLEVEs have shown; they should be used to estimate the probable overpressure.

4. In the case of cylindrical tanks, experimental data indicate that overpressure is higher on the direction of the tank main axis than on the direction perpendicular to it, this effect being important at short distances. 
5. There is some uncertainty associated to the respective contributions to blast of the expansion of the vapour phase present before the burst (practically instantaneous) and of the liquid flash (slower); a conservative approach is to consider both simultaneously.

6. It has been observed that, when using the TNT equivalent mass curve, results are different than when the Sachs scaled distance is used, the latter giving lower results.

7. Further experimental work is still needed to improve the knowledge of overpressure from BLEVEs. Important points would be the amount of energy released invested really in creating overpressure, the respective contributions of the vapour phase present before the burst and of the liquid flash, and the directional effects in the case of cylindrical tanks. However, due to the diverse uncertainty factors aforementioned, one may think that it will always exist some uncertainty in its prediction for a given case.

\section{Acknowledgements}

The authors thank the Spanish Ministry of Economy and Competitiveness (project no. CTM2014-57447-R) for financial support. They also acknowledge Dr. E. W. Lemmon (NIST) for the information given.

\section{References}

Abbasi, T., Abbasi, S. A., 2007. The boiling liquid expanding vapour explosion (BLEVE): Mechanism, consequence assessment, management. J. Hazard. Mater., 141 (3), 489-519. doi: dx.doi.org/10.1016/j.jhazmat.2006.09.056.

Birk, A. M., VanderSteen, J. D. J., 2006. On the transition from non-BLEVE to BLEVE failure for a $1.8 \mathrm{~m}^{3}$ propane tank. J. Press. Vessel Technol, 128 (4), 648655.

Birk, A. M., Davison, C., Cunningham, M., 2007. Blast overpressures from medium scale BLEVE tests. J. Loss Prev. Process Ind., 20 (3), 194-206. doi: dx.doi.org/10.1016/j.jlp.2007.03.001.

Birk, A. M., 2012. Scale considerations for fire testing of pressure vessels used for dangerous goods transportation. J. Loss Prev. Process Ind., 25 (3), 623-630. 
Brode, H. L., 1959. Blast wave from a spherical charge. The Physics of Fluids, 2 (2), 217-229.

Bubbico, R., Marchini, M., 2008. Assessment of an explosive LPG release accident: A case study. J. Hazard. Mater., 155 (3), 558-565. doi:dx.doi.org/10.1016/j.jhazmat.2007.11.097.

Casal, J., Salla, J. M., 2006. Using liquid superheating energy for a quick estimation of overpressure in BLEVEs and similar explosions. J. Hazard. Mater., 137 (3), $1321-1327$.

Casal, J., 2008. Evaluation of the Effects and Consequences of Major Accidents in Industrial Plants. Elsevier, Amsterdam.

CCPS, 1994. Guidelines for evaluating the characteristics of vapour cloud, explosions, flash fires and BLEVEs. CCPS-AIChE, New York.

CCPS, 2010. Guidelines for Vapor Cloud Explosion, Pressure Vessel Burst, BLEVE, and Flash Fire Hazards, 2nd Edition. Wiley Subscription Services, Inc., A. Wiley Company, New York.

Crowl, D. A., 1991. Using thermodynamic availability to determine the energy of explosion. Plant/Operations Progress, 10 (3), 136-142. doi: 10.1002/prsb.720100306.

Crowl, D. A., 1992. Using thermodynamic availability to determine the energy of explosion for compressed gases. Plant/Opererations Progr., 11 (2), 47-49. doi: 10.1002/prsb.720110206.

Crowl, D. A., 2010. Understanding explosions, John Wiley and Sons, New York.

Hemmatian, B., Planas, E., Casal, J., 2015. Fire as a primary event of accident domino sequences: the case of BLEVE. Reliability Eng. Syst. Safety, 139, 141148.doi: dx.doi.org/10.1016/j.ress.2015.03.021.

Hemmatian, B., Planas, E., Casal, J., 2016. On BLEVE definition, the significance of superheat limit temperature $\left(\mathrm{T}_{\mathrm{sl}}\right)$ and LNG BLEVE's. J. Loss Prev. Process Ind., 40, 81.doi: 10.1016/j.jlp.2015.12.001.

Johnson, D. M., Pritchard, J. M., Wickens, M. J., 1991. Large scale experimental study of Boiling Liquid expanding Vapour Explosions (BLEVEs). Contract report 15367, Project M8411, British Gas: Research and Technology division.

Laboureur, D., Heymes, F., Lapebie, E., Buchlin, J., Rambaud, P., 2014. BLEVE overpressure: multiscale comparison of blast wave modeling. Process Safety Progress, 33(3), 274-284.

Laboureur, D., Birk, A. M., Buchlin, J. M., Rambaud, P., Aprin, L., Heymes, F., Osmont, A., 2015. A closer look at BLEVE overpressure. Process Saf. Environ. Prot., 95, 159-171. 
Lemmon, E., McLinden, M., Huber, M., 2007. REFPROP: Reference fluid thermodynamic and transport properties. NIST standard reference database, 23(8.0).

Ogle, R. A., Ramirez, J. C., Smyth, S. A., 2012. Calculating the explosion energy of a boiling liquid expanding vapour explosion using exergy analysis. Process Saf. Progr., 31 (1), 51-54. doi: dx.doi.org/10.1002/prs.10465

Piñeiro, G., Perelman, S., Guerschman, J. P., Paruelo, J. M., 2008. How to evaluate models: Observed vs. predicted or predicted vs. observed? Ecological Mod., 216 (3-4), 316-322. doi: doi: dx.doi.org/10.1016/j.ecolmodel.2008.05.006

Planas Cuchi , E., Salla , J. M., Casal , J., 2004. Calculating overpressure from BLEVE explosions. J. Loss Prev. Process Ind., 17 (6), 431-436. doi: dx.doi.org/10.1016/j.jlp.2004.08.002.

Planas, E. and Casal, J. 2015. BLEVE-Fireball. Handbook of Combustion. 1:21:1-25. Wiley-VCM. Weinheim, 2015.

Prugh, R. W., 1991. Quantitative Evaluation of "BLEVE” Hazards. J. Fire Prot. Eng., 3 (1), 9-24.

Reid, R.C., 1979. Possible mechanism for pressurized-liquid tank explosions or BLEVE's. Science, 203, 1263-1265.

Roberts, M. W., 2000. Analysis of Boiling Liquid Expanding Vapour Explosion (BLEVE) at DOE Sites. In ProceedingsSA-2000 Safety Analysis Working Group Workshop 2000. "Building a Bridge to the 21st Century - Development and Maintenance of Core Safety Analysis Capability" (1-20). Los Alamos National Laboratory, Los Alamos, New Mexico.

Salla, J. M., Demichela, M., Casal, J., 2006. BLEVE: A new approach to the superheat limit temperature. J. Loss Prev. Process Ind., 19 (6), 690-700. doi: dx.doi.org/10.1016/j.jlp.2006.04.004.

Smith, J. M., Van Ness, H. C., 1996. Introduction to chemical engineering thermodynamics (5th Ed.). McGraw-Hill, Inc., New York.

\section{Nomenclature}

$\Delta B \quad$ Batch availability, $\mathrm{J} \cdot \mathrm{mol}^{-1}$

$c_{p_{V}} \quad$ Specific heat of the vapour, $\mathrm{J} \cdot \mathrm{mol}^{-1} \cdot \mathrm{K}^{-1}$

$c_{p_{L, T b}}$ Specific heat of the liquid at atmospheric-pressure boiling point, $\mathrm{J} \cdot \mathrm{kg}^{-1} \cdot \mathrm{K}^{-1}$

E Explosion energy considering only the expansion of the vapour phase present before the burst, $\mathrm{J}$ 
$E^{*} \quad$ Explosion energy considering the expansion of the vapour phase present before the burst plus the vapour generated in the flashing of the liquid, $\mathrm{J}$

$E_{w} \quad$ Part of the explosion energy used to generate the pressure wave, $\mathrm{J}$

$f \quad$ Mass fraction of liquid vaporized in the depressurization, --

$h_{L 0} \quad$ Enthalpy of the liquid in the vessel at atmospheric-pressure boiling point, $\mathrm{J}_{\mathrm{kg}} \mathrm{kg}^{-1}$

$h_{L} \quad$ Enthalpy of the liquid in the vessel at conditions just before the explosion, $\mathrm{J}_{\mathrm{kg}} \mathrm{kg}^{-1}$

$\Delta h_{v, T b}$ Latent heat of vaporization at atmospheric-pressure boiling point, $\mathrm{J} \cdot \mathrm{kg}^{-1}$

$\Delta H_{c} \quad$ Heat of combustion of the fuel, $\mathrm{J} \cdot \mathrm{kg}^{-1}$

$\Delta H_{T N T}$ TNT explosion energy, $\mathrm{J} \cdot \mathrm{kg}^{-1}$

$L \quad$ Volume of liquid in the vessel just before the explosion, $\mathrm{m}^{3}$

$m_{L 0} \quad$ Mass of liquid at the final state of the isentropic process, $\mathrm{kg}$

$m_{L} \quad$ Mass of liquid in the vessel at conditions just before explosion, $\mathrm{kg}$

$m_{T} \quad$ Total mass of the vessel content, $\mathrm{kg}$

$m_{T N T} \quad$ Equivalent mass of TNT, kg

$m_{V} \quad$ Mass of vapour in the vessel at conditions just before explosion, $\mathrm{kg}$

$m_{V 0} \quad$ Mass of vapour at the final state of the isentropic process, $\mathrm{kg}$

$P \quad$ Pressure in the vessel just before explosion, $\mathrm{Pa}$

$P_{c} \quad$ Critical pressure, $\mathrm{Pa}$

$P_{0} \quad$ Atmospheric pressure, $\mathrm{Pa}$

$P_{\text {rup }} \quad$ Failure pressure, $\mathrm{Pa}$

$P_{S} \quad$ Overpressure at a given distance, $\mathrm{Pa}$

$r_{0} \quad$ Distance between the centre of the explosion and the point at which the overpressure has to be estimated, $\mathrm{m}$

$R \quad$ Ideal gas constant, $8.3145 \mathrm{~J} \cdot \mathrm{mol}^{-1} \cdot \mathrm{K}^{-1}$

$\bar{R} \quad$ Scaled distance, $\mathrm{m} \cdot \mathrm{kg}^{-1 / 3}$

$R_{S} \quad$ Sachs scaled distance, --

$S_{L} \quad$ Specific entropy of the liquid at conditions just before explosion, $\mathrm{J} \cdot \mathrm{kg}^{-1} \cdot \mathrm{K}^{-1}$

$S_{L 0} \quad$ Specific entropy of the liquid at the final state of the adiabatic process, $\mathrm{J} \cdot \mathrm{kg}^{-1} \cdot \mathrm{K}^{-1}$ 
$S_{V} \quad$ Specific entropy of the vapour at conditions just before explosion, $\mathrm{J} \cdot \mathrm{kg}^{-1} \cdot \mathrm{K}^{-1}$

$S_{V 0} \quad$ Specific entropy of the vapour at the final state of the adiabatic process, $\mathrm{J} \cdot \mathrm{kg}^{-1} \cdot \mathrm{K}^{-1}$

$S E \quad$ Superheating energy of liquid, $\mathrm{kJ} \cdot \mathrm{kg}^{-1}$ or $\mathrm{MJ} \cdot \mathrm{m}^{-3}$

$T \quad$ Temperature of the vapour in the vessel just before the explosion, $\mathrm{K}$

$T_{b} \quad$ Atmospheric-pressure boiling point, $\mathrm{K}$

$T_{c} \quad$ Critical temperature, $\mathrm{K}$

$T_{0} \quad$ Ambient temperature, $\mathrm{K}$

$T_{s l} \quad$ Superheat limit temperature, $\mathrm{K}$

$u_{L} \quad$ Specific internal energy of the liquid at conditions just before explosion, $\mathrm{J} \cdot \mathrm{kg}^{-1}$

$u_{L 0} \quad$ Specific internal energy of the liquid at the final state of the adiabatic process, $\mathrm{J} \mathrm{kg}^{-1}$

$u_{V} \quad$ Specific internal energy of the vapour at conditions just before explosion, $\mathrm{J} \cdot \mathrm{kg}^{-1}$

$u_{V 0} \quad$ Specific internal energy of the vapour at the final state of the adiabatic process, $\mathrm{J} \cdot \mathrm{kg}^{-1}$

$U \quad$ Overall internal energy of the vessel at conditions just before the explosion, $\mathrm{J}$

$\Delta U \quad$ Overall variation of the internal energy of the vessel content, $\mathrm{J}$

$v_{V 0} \quad$ Specific volume of vapour at the final state of the adiabatic process, $\mathrm{m}^{3} \cdot \mathrm{kg}^{-1}$

$v_{L 0} \quad$ Specific volume of liquid at the final state of the adiabatic process, $\mathrm{m}^{3} \cdot \mathrm{kg}^{-1}$

$V \quad$ Volume of vapour in the vessel just before the explosion, $\mathrm{m}^{3}$

$V_{f} \quad$ Volume of vapour generated in the flashing of the liquid, $\mathrm{m}^{3}$

$V_{T} \quad$ Total vessel volume, $\mathrm{m}^{3}$

$V^{*} \quad$ Total volume of vapour contributing to the explosion at conditions just before the explosion, $\mathrm{m}^{3}$

$\Delta V \quad$ Volume variation of the total content of the vessel when going from the explosion state to atmospheric pressure conditions, $\mathrm{m}^{3}$

$x \quad$ Vapour fraction (with respect to the total mass) at the final state of the adiabatic irreversible process

$x_{V} \quad$ Fraction of the vapour mass at explosion state that does not condense when going to the final state of the isentropic process

$x_{L} \quad$ Fraction of the liquid mass at explosion state that flashes to vapour when going to the final state of the isentropic process 


\section{Greek Letters}

$\beta \quad$ Fraction of the explosion energy converted into blast wave, --

$\gamma \quad$ Ratio of constant pressure to constant volume specific heats of the gas in the vessel, --

$\rho_{V} \quad$ Density of the saturated vapour at conditions just before explosion, $\mathrm{kg} \cdot \mathrm{m}^{-3}$

$\rho_{L} \quad$ Density of the saturated liquid at conditions just before explosion, $\mathrm{kg} \cdot \mathrm{m}^{-3}$

\section{Appendix}

\section{Mechanical energy models}

\section{Constant volume energy addition (CV)}

The model considered within this thermodynamic assumption is the one from Brode (1959) :

$$
\begin{gathered}
E=\frac{\left(P-P_{0}\right) \cdot V}{(\gamma-1)} \\
E^{*}=\frac{\left(P-P_{0}\right) \cdot V^{*}}{(\gamma-1)}
\end{gathered}
$$

\section{Isothermal expansion (IE)}

Within this thermodynamic assumption the model considered is the one from Smith et al. (1996):

$$
\begin{gathered}
E=P \cdot V \cdot \ln \left(\frac{P}{P_{0}}\right) \\
E^{*}=P \cdot V^{*} \cdot \ln \left(\frac{P}{P_{0}}\right)
\end{gathered}
$$

\section{Thermodynamic availability (TA)}

Crowl $(1991,1992)$ was the author which developed the model considering this thermodynamic assumption: 


$$
\begin{aligned}
E & =\left(\frac{P \cdot V}{R \cdot T}\right) \cdot \Delta B \\
E^{*} & =\left(\frac{P \cdot V^{*}}{R \cdot T}\right) \cdot \Delta B
\end{aligned}
$$

where $\Delta B$ is the batch availability which has to be obtained from:

$$
\Delta B=c_{p_{V}} \cdot \Delta T-c_{p_{V}} \cdot T_{0} \cdot \ln \left(\frac{T_{0}}{T}\right)-R \cdot T_{0} \cdot \ln \left(\frac{P}{P_{0}}\right)-R \cdot T \cdot\left(\frac{P_{0}}{P}-1\right)
$$

\section{Ideal gas behaviour and isentropic expansion (IISE)}

The most used model within this thermodynamic assumption is the one from Prugh, 1991:

$$
\begin{aligned}
& E=\frac{P \cdot V}{\gamma-1} \cdot\left[1-\left(\frac{P_{0}}{P}\right)^{\frac{\gamma-1}{\gamma}}\right] \\
& E^{*}=\frac{P \cdot V^{*}}{\gamma-1} \cdot\left[1-\left(\frac{P_{0}}{P}\right)^{\frac{\gamma-1}{\gamma}}\right]
\end{aligned}
$$

\section{Real gas behaviour and isentropic expansion (RISE)}

The most used model within this thermodynamic assumption is the one from CCPS (2010):

$$
\begin{gathered}
E=\Delta U_{V}=m_{V} \cdot\left(u_{V 0}-u_{v}\right) \\
E^{*}=\Delta U=m_{L 0} \cdot u_{L 0}+m_{V 0} \cdot u_{V 0}-m_{L} \cdot u_{L}-m_{V} \cdot u_{v}
\end{gathered}
$$

where the mass of vapour $\left(m_{V 0}\right)$ and liquid $\left(m_{L 0}\right)$ at the final state of the isentropic expansion can be obtained from the following equations: 


$$
\begin{gathered}
m_{V 0}=x_{L} \cdot m_{L}+x_{V} \cdot m_{v} \\
m_{L 0}=\left(1-x_{L}\right) \cdot m_{L}+\left(1-x_{V}\right) \cdot m_{v}
\end{gathered}
$$

The mass fraction of liquid that flashes to vapour during the explosion $\left(x_{L}\right)$, and the mass fraction of vapour that does not condense $\left(x_{V}\right)$ can be obtained from the following equations:

$$
\begin{gathered}
x_{L}=\frac{s_{L}-s_{L 0}}{s_{V 0}-s_{L 0}} \\
x_{V}=\frac{s_{V}-s_{L 0}}{s_{V 0}-s_{L 0}}
\end{gathered}
$$

\section{Real gas behaviour and adiabatic irreversible expansion (RAIE)}

Two methods are considered within this assumption, the one proposed by Planas Cuchi et al. (2004) identified here with RAIE abbreviation:

$$
\begin{gathered}
E^{*}=-\left[\left(u_{L 0}-u_{V 0}\right) \cdot m_{T} \cdot x-m_{T} \cdot u_{L 0}+U\right] \\
x=\frac{m_{T} \cdot P \cdot v_{L 0}-V_{T} \cdot P+m_{T} \cdot u_{L 0}-U}{\left[\left(u_{L 0}-u_{V 0}\right)-\left(v_{V 0}-v_{L 0}\right) \cdot P\right] \cdot m_{T}}
\end{gathered}
$$

and the method proposed by Casal and Salla (2006), in the paper abbreviated by (SE):

$$
S E=h_{L}-h_{L 0}
$$

These authors demonstrated that, for an isentropic process (assuming that $50 \%$ of the energy released was devoted to braking the vessel and ejecting the fragments; see last paragraph of this section), if an irreversible (much more realistic) process is assumed, only $5 \%$ of $S E$ originates blast; this percentage was introduced through a constant $k$ :

$$
E_{w}=k \cdot m_{L} \cdot S E
$$

However, in this study, in order to make possible the comparative analysis, $\mathrm{k}$ values have been lightly changed, assuming that only $40 \%$ (instead of $50 \%$ ) of the energy participates in resulting BLEVE blast. So, we have: 
$k=0.04$ for irreversible process.

In this paper, the irreversible process has been considered for the comparative analysis. 